\title{
Surto de pitiose cutânea em bovinos ${ }^{1}$
}

\author{
Adriane L. Gabriel ${ }^{2}$, Glaucia D. Kommers ${ }^{3 *}$, Maria E. Trost ${ }^{2}$, Claudio S.L. \\ Barros $^{3}$, Daniela B. Pereira ${ }^{4}$, Stela E. Schwendler ${ }^{4}$ e Janio M. Santurio ${ }^{4}$
}

\begin{abstract}
Gabriel A.L., Kommers G.D., Trost M.E., Barros C.S.L., Pereira D.B., Schwendler S.E. \& Santurio J.M. 2008. [Outbreak of cutaneous pythiosis in cattle.] Surto de pitiose cutânea em bovinos. Pesquisa Veterinária Brasileira 28(12):583-587. Departamento de Patologia, Universidade Federal de Santa Maria, Camobi, Santa Maria, RS 97105-900, Brazil. E-mail: glaukommers@yahoo.com

Seventy-six young mixed breed cattle of both sexes, presented multifocal ulcerated nodular cutaneous lesions localized in the medial and lateral aspects of fore and hindlimbs, ventral neck, sternum, and tail. The disease occurred during summer and lesions were observed on areas of the body which were in contact with water of irrigation channels for long periods. Histologically, there were multiple granulomas and pyogranulomas with few negative profiles of hyphae, which were better visualized throughout Grocott methenamine silver stain. Definitive etiologic diagnosis was based on immunohistochemistry with anti-Pythium insidiosum polyclonal antibody. Additionally, an indirect ELISA test was performed. Bovine cutaneous pythiosis outbreaks are uncommon and, particularly as occurred in the cattle of this report, all affected animals had spontaneous healing within two to three weeks.
\end{abstract}

INDEX TERMS: Pythiosis, Pythium insidiosum, diseases of cattle, immunohistochemistry, ELISA test, pathology.

RESUMO.- Setenta e seis bovinos, sem raça definida, jovens, de ambos os sexos, apresentaram lesões cutâneas multifocais nodulares, ulceradas e crostosas nas faces medial e lateral dos membros anteriores e posteriores, região ventral do pescoço, esterno e cauda. A doença ocorreu no verão e as lesões foram observadas nas regiões do corpo que ficavam grande tempo em contato com a água em canais de irrigação. Histologicamente observaram-se múltiplos granulomas e piogranulomas contendo escassas imagens negativas de hifas na área central, as quais foram melhor evidenciadas através da técnica de metenamina nitrato de prata de Grocott. O diagnóstico etiológico definitivo foi baseado na técnica de imuno-histoquímica com an-

\footnotetext{
${ }^{1}$ Recebido em 30 de maio de 2008.

Aceito para publicação em 24 de junho de 2008.

2 Programa de Pós-Graduação em Medicina Veterinária, área de concentração em Patologia Veterinária, Centro de Ciências Rurais, Universidade Federal de Santa Maria (UFSM).

${ }^{3}$ Laboratório de Patologia Veterinária, Departamento de Patologia, UFSM, Camobi, Santa Maria, RS 97105-900, Brasil. *Autor para correspondência: glaukommers@yahoo.com

${ }^{4}$ Laboratório de Pesquisas Micológicas, Departamento de Microbiologia e Parasitologia, UFSM, Santa Maria, RS.
}

ticorpo policlonal anti-Pythium insidiosum. Adicionalmente, foi realizado o teste de ELISA indireto. Surtos de pitiose cutânea bovina são incomuns e, particularmente neste relato, todos os animais afetados tiveram cura espontânea das lesões dentro de duas a três semanas.

TERMOS DE INDEXAÇÃO: Pitiose, Pythium insidiosum, doenças de bovinos, imuno-histoquímica, teste de ELISA, patologia.

\section{INTRODUÇÃO}

A pitiose é uma enfermidade causada pelo oomiceto Pythium insidiosum; é relatada em humanos e em várias espécies de animais domésticos (incluindo eqüinos, cães, gatos, bovinos e ovinos) em diferentes países do mundo (Mendoza \& Newton 2005). O agente, que pertence ao Reino Straminipila (Mendoza et al. 2005), Filo Oomycota, Classe Oomycetes, Ordem Peronosporales e Família Pythiaceae (Alexopoulos et al. 1996), requer um ambiente aquático com substrato orgânico para manutenção do seu ciclo de vida e temperatura entre $30^{\circ}$ e $40^{\circ} \mathrm{C}$ para reprodução (Chaffin et al. 1995). Verões chuvosos propiciam um ambiente ideal para a ocorrência da infecção (Miller \& Campbell 1982).

A pitiose cutânea em bovinos foi primeiramente descrita por Miller et al. (1985) e são conhecidos somente mais 
dois relatos da doença nessa espécie animal (Santurio et al. 1998, Pérez et al. 2005). A julgar pela informação nesses três relatos, não há aparente predisposição por sexo e a maioria dos animais afetados é jovem. As lesões macroscópicas caracterizam-se por espessamentos dérmicos ulcerados, multifocais, de tamanhos variados, localizados principalmente nos membros. Algumas lesões não são ulceradas ou apresentam tratos fistulosos com material serossanguinolento ou purulento. Histologicamente observam-se múltiplos granulomas dérmicos discretos, áreas de necrose multifocal e tecido fibroso circundando os granulomas. Há poucas hifas pobremente coradas no centro dos granulomas e no interior de células gigantes multinucleadas. As hifas são melhor visualizadas na impregnação pela prata para fungos, têm cerca de 4-9zm de diâmetro, são ramificadas e raramente septadas. Reação semelhante ao fenômeno de Splendore-Hoeppli circundando as hifas, também foi relatada.

O diagnóstico presuntivo de pitiose, especialmente na espécie eqüina, pode ser feito com base nas características clínicas e aspectos morfológicos das lesões (Chaffin et al. 1995). O cultivo e identificação do agente são utilizados no estabelecimento do diagnóstico definitivo (Chaffin et al. 1995, Ginn et al. 2007). Técnicas de imunohistoquímica (Brown et al. 1988), imunofluorescência e testes sorológicos (Mendoza et al. 1996) também constituemse em ferramentas muito importantes para estabelecer o diagnóstico definitivo da doença (Santurio et al. 2006a).

O objetivo deste trabalho é relatar a ocorrência de um surto de pitiose cutânea em bovinos, no estado do Rio Grande do Sul, e descrever os achados epidemiológicos, clínico-patológicos e a aplicação da técnica de imunohistoquímica no diagnóstico definitivo dessa doença.

\section{MATERIAL E MÉTODOS}

Setenta e seis bovinos, sem raça definida, de ambos os sexos, com poucos meses até três anos de idade, provenientes de uma propriedade da região Oeste do Rio Grande do Sul, apresentaram lesões cutâneas entre os meses de janeiro e fevereiro de 2005. Biópsia cutânea (múltiplas seções de um bovino), fixada em formol a $10 \%$, foi encaminhada para exame histopatológico, histoquímico e imuno-histoquímico (IHQ) no Laboratório de Patologia Veterinária da Universidade Federal de Santa Maria (LPV-UFSM). Foram confeccionadas lâminas histológicas coradas pela hematoxilina e eosina (HE) e realizadas as técnicas histoquímicas do ácido periódico de Schiff (PAS) e da metenamina nitrato de prata de Grocott (GMS).

Para a técnica de IHQ, foram utilizadas lâminas silanizadas com seções histológicas de 3zm. Após a desparafinização e reidratação dos tecidos, foi realizado quando necessário, o bloqueio da peroxidase endógena através do uso de peróxido de hidrogênio (10 volumes), seguido da recuperação antigênica com solução de TRIS-EDTA (pH 9,0) em forno microondas em potência máxima por 10 minutos. O bloqueio das reações inespecíficas foi realizado com solução de caseína (30 minutos em temperatura ambiente). Como anticorpo primário foi utilizado um anticorpo policlonal (não comercial) anti-Pythium insidiosum produzido em coelho, diluído (1:1000) em PBST e adicionado aos cortes histológicos por 60 minutos a $37^{\circ} \mathrm{C}$. O anticorpo secundário biotinilado e o complexo estreptavidinaperoxidase (LSAB+System-HRP, Dako Cytomation, K0690) ou estreptavidina-fosfatase alcalina (LSAB+System-AP, Dako Cytomation, K0689) foram utilizados consecutivamente, incubados à temperatura ambiente por 30 minutos, e marcados através da adição do cromógeno de tetracloreto de 33'diaminobenzidina (DAB, Sigma D-5637) ou Liquid Permanent Red (Dako Cytomation, K0640), respectivamente. As seções histológicas foram contracoradas com hematoxilina de Harris (quando marcadas com DAB) ou de Mayer (quando marcadas com Liquid Permanent Red), desidratadas e montadas com resina sintética e lamínulas. Como controle positivo foram utilizadas seções histológicas de caso confirmado de pitiose equina. Como controles negativos foram utilizadas as mesmas seções a serem testadas, com a substituição do anticorpo primário por diluente de anticorpo (PBST).

Material proveniente das lesões e soro de 10 bovinos (do lote afetado) foram remetidos ao Laboratório de Pesquisas Micológicas (LAPEMI-UFSM) para a realização da cultura microbiológica e do teste de ELISA (Ensaio de Imunoadsorção Enzimática) indireto, respectivamente. Para o isolamento de $P$. insidiosum, pequenos fragmentos do tecido fresco, previamente lavados em solução de antibióticos e água destilada estéril, foram semeados em tubos contendo caldo Sabouraud, agar Meio Mínimo e Corn Meal agar, permanecendo incubados a $37^{\circ} \mathrm{C}$, por $24-48$ horas. $O$ teste de ELISA indireto foi realizado conforme Santurio et al (2006b).

\section{RESULTADOS}

Os bovinos deste estudo não tinham raça definida, eram de ambos os sexos, tinham idades variando de poucos meses até três anos e eram mantidos em um campo com canais de irrigação, passando parte do tempo pastando dentro desses canais. Os casos ocorreram no verão, nos meses de janeiro e fevereiro.

As lesões cutâneas localizavam-se nas faces medial e lateral dos membros anteriores e posteriores, região ventral do pescoço e esterno (Fig.1) e, eventualmente, na cau-

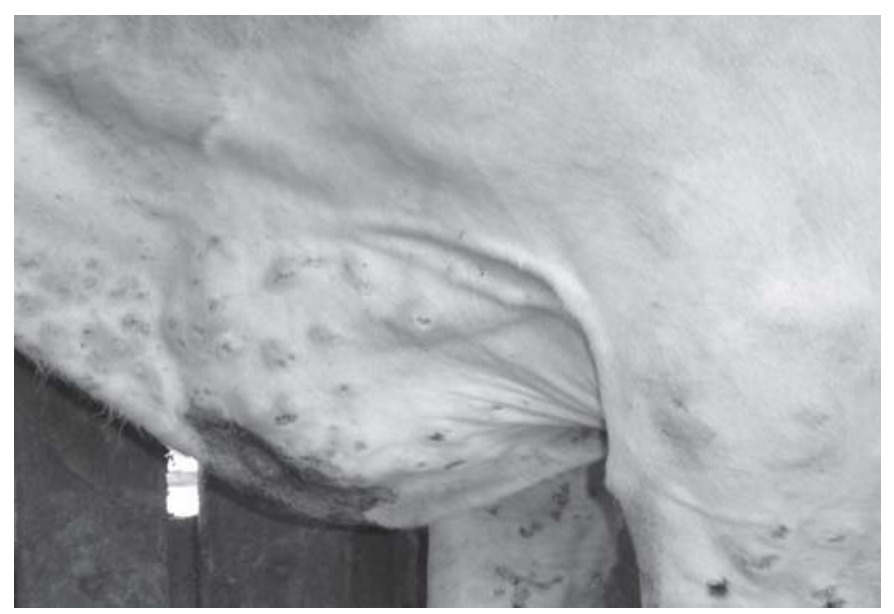

Fig.1.Bovino afetado por pitiose cutânea com lesões nodulares multifocais localizadas na pele da região ventral do pescoço e esterno e nas faces medial e lateral dos membros anteriores. 

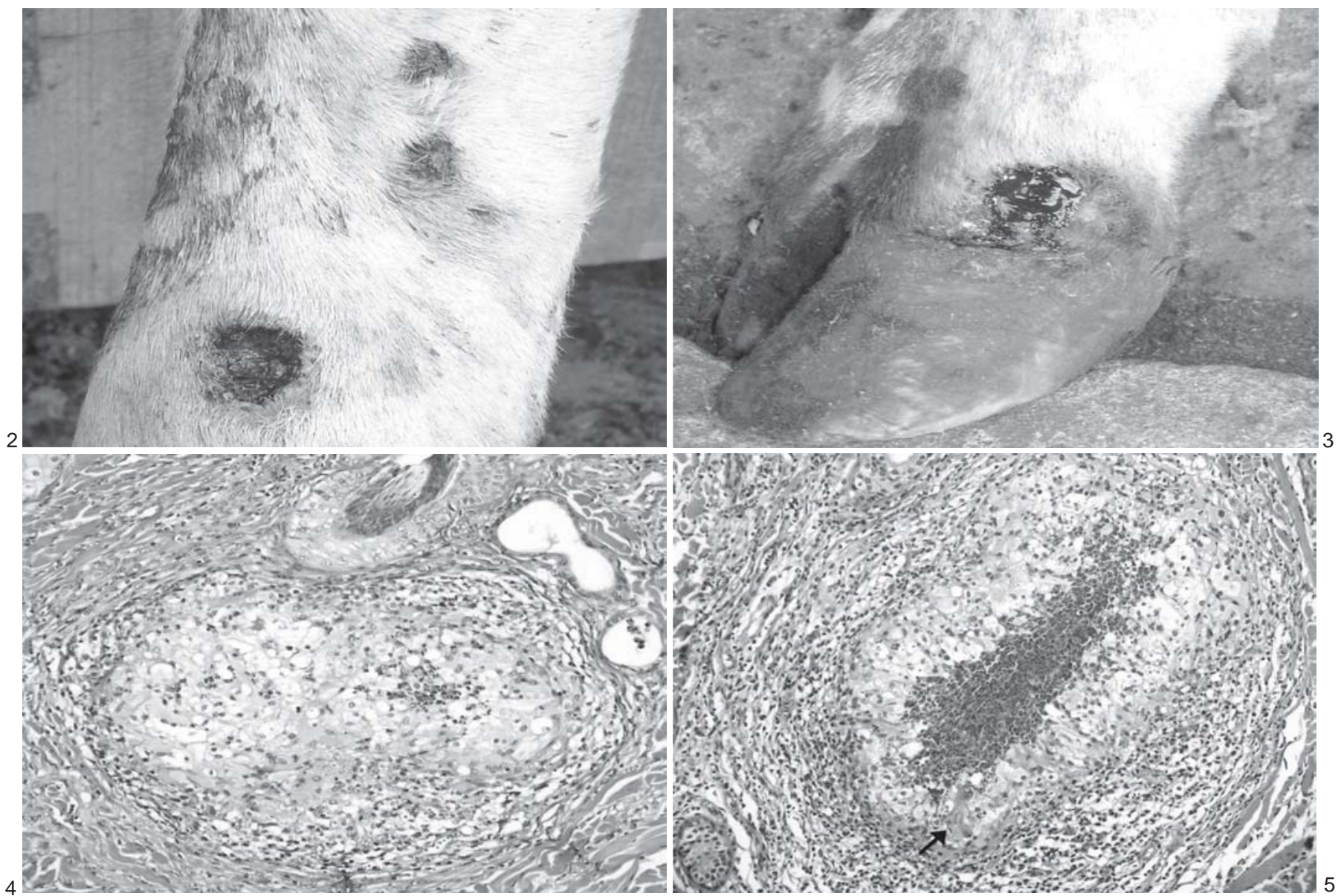

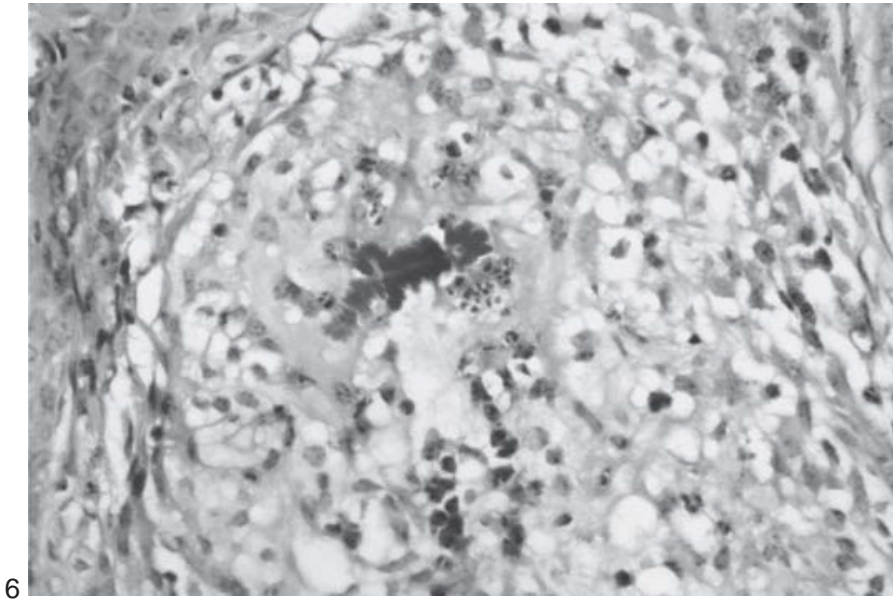

da (três animais) e caracterizavam-se principalmente por elevações nodulares multifocais de tamanhos variados, que evoluíam rapidamente para úlceras recobertas por crostas (Fig.2 e 3), algumas drenando exsudato purulento.

Histologicamente, na derme superficial e principalmente na derme profunda, observaram-se múltiplos granulomas e piogranulomas bem circunscritos (Fig.4 e 5), com neutrófilos e eosinófilos no centro e grande quantidade de macrófagos e algumas células gigantes multinucleadas na periferia. Nas áreas centrais dos granulomas havia algumas seções transversais e longitudinais de hifas
Fig.2. Lesões ulcerativas multifocais no membro anterior de bovino afetado por pitiose cutânea.

Fig.3. Bovino com pitiose cutânea com lesão ulcerativohemorrágica na pele próxima à coroa do casco.

Fig.4. Aspecto histológico da pitiose cutânea em bovinos mostrando granulomas dérmicos coalescentes com raros eosinófilos na região central. HE, obj.10x.

Fig.5. Aspecto histológico da pitiose cutânea em bovinos mostrando piogranuloma bem circunscrito na derme, com imagem negativa de hifa intralesional (seta). HE, obj.10x.

Fig.6. Aspecto histológico da pitiose cutânea em bovinos mostrando imagem negativa de hifa ramificada circundada por reação de Splendore-Hoeppli no centro de um granuloma dérmico. HE, obj.20x.

não-coradas, muitas vezes circundadas por material radiado eosinofílico, morfologicamente compatível com reação de Splendore-Hoeppli (Fig.6). Na técnica de metenamina nitrato de prata de Grocott (GMS) foram observadas hifas, com aproximadamente 4-9zm de diâmetro, ramificadas e raramente septadas no centro dos granulomas. As hifas não se coraram pela técnica do ácido periódico de Schiff (PAS).

Através da técnica de IHQ obteve-se forte imunomarcação positiva das hifas para Pythium insidiosum (Fig.7 e 8). No teste de ELISA indireto, oito dos ani- 


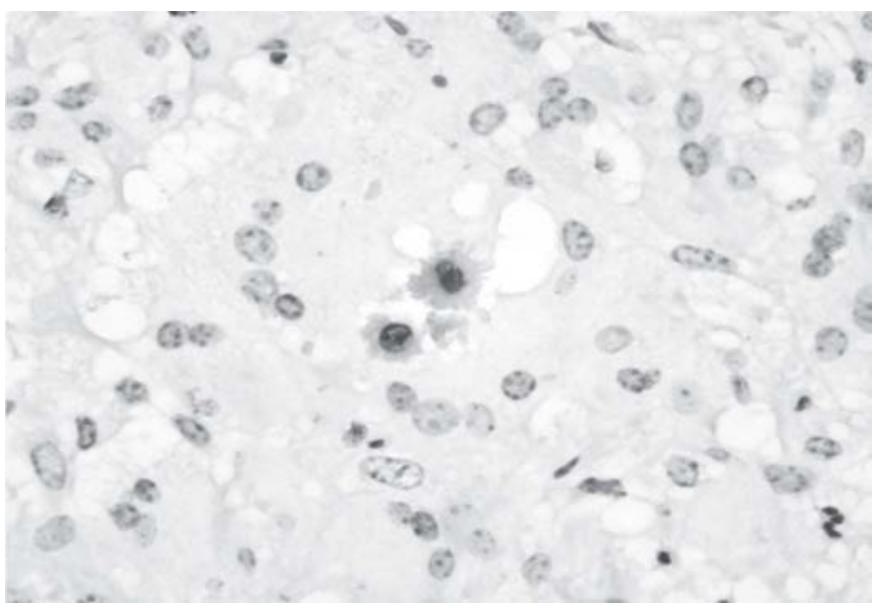

Fig.7. Técnica imuno-histoquímica (método da estreptavidinabiotina-peroxidase) aplicada a lesão de pele de bovino afetado por pitiose cutânea. Há várias seções longitudinais de hifas fortemente imunomarcadas em um granuloma, obj.20x.

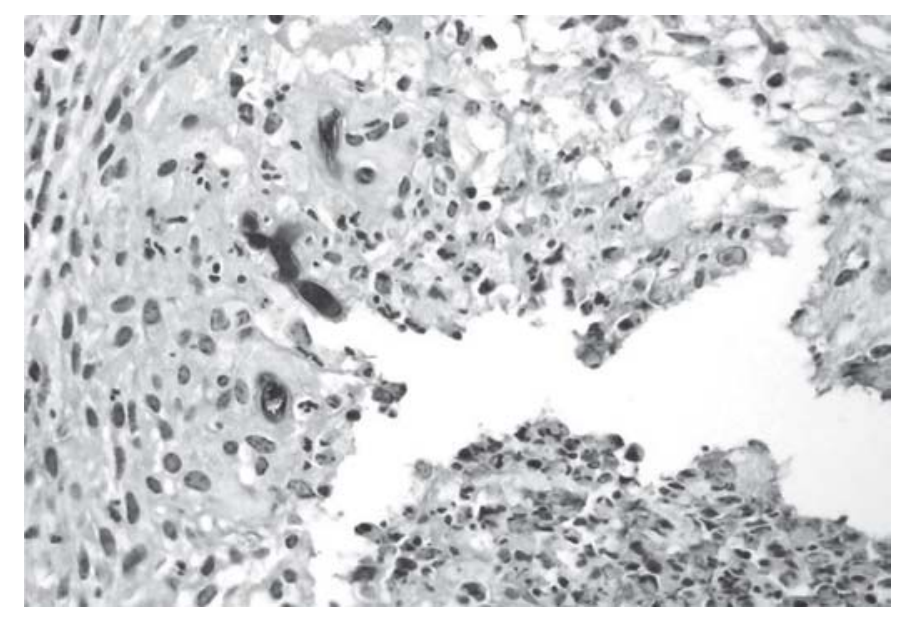

Fig.8. Técnica imunoistoquímica (método da estreptavidinabiotina-fosfatase alcalina) aplicada a lesão de pele de bovino afetado por pitiose cutânea Há duas seções transversais de hifas fortemente imunomarcadas (circundadas por reação de Splendore-Hoeppli) em um granuloma, obj.40x.

mais testados tiveram reação considerada positiva (com densidades óticas variando entre 0,099 e 0,279; ponto de corte $=0,095)$, corroborando com o diagnóstico de pitiose estabelecido pela IHQ. Não foi possível isolar o agente através da cultura, pois o material encaminhado (crostas dessecadas) foi inadequado.

Todos os animais afetados recuperaram-se totalmente dentro de duas a três semanas sem tratamento. Foram relatados cinco novos casos no mesmo local e época do ano no ano seguinte, também com cura espontânea das lesões.

\section{DISCUSSÃO}

A infecção pelo oomiceto Pythium insidosum tem sido associada ao contato dos animais com águas contamina- das sob temperaturas elevadas, onde ocorre a liberação de zoósporos móveis biflagelados (Chaffin et al. 1995). Os bovinos deste relato estavam pastoreando em campos permeados por canais de irrigação, permanecendo em contato com a água sob temperatura ambiente elevada, condições essas plenamente favoráveis para a ocorrência da doença. A presença de lesões somente nas regiões do corpo em contato com a água, também concordam com o descrito na literatura para pitiose cutânea eqüina (Miller \& Campbell 1982).

Bovinos infectados podem apresentar clinicamente prurido, edema e claudicação, além de infecções bacterianas secundárias nas regiões lesionadas (Pérez et al. 2005), semelhantemente ao que é descrito na pitiose cutânea eqüina (Leal et al. 2001).

Lesões macroscópicas multifocais nodulares e/ou ulceradas estão de acordo com as descritas nos outros relatos de pitiose bovina (Miller et al. 1985, Santurio et al. 1998, Pérez et al. 2005) e diferem das alterações observadas em eqüinos, onde as lesões cutâneas são na grande maioria das vezes únicas e localmente extensas (Miller \& Campbell 1982). Uma diferença macroscópica marcante da pitiose bovina em relação à eqüina está na ausência dos "kunkers" (Santurio et al. 1998, Pérez et al. 2005), que são massas firmes irregulares formadas por eosinófilos desintegrados preenchendo tratos fistulosos (Chaffin et al. 1995, Mendoza et al. 1996). Os achados histopatológicos observados neste e nos demais relatos de pitiose bovina (Miller et al. 1985, Santurio et al. 1998, Pérez et al. 2005) revelam inflamação granulomatosa ou piogranulomatosa, diferindo grandemente das lesões observadas em eqüinos, onde há intenso infiltrado eosinofílico formando áreas focalmente extensas de eosinófilos necróticos (kunkers), circundadas por tecido de granulação (Chaffin et al. 1995).

A cura espontânea em casos de pitiose bovina, como vista neste estudo, também foi descrita por Santurio et al. (1998). Talvez uma diferença no tipo de resposta imunológica/inflamatória possa explicar esse fato, pelo menos parcialmente. Eqüinos infectados desenvolvem uma resposta tecidual constituída predominantemente por eosinófilos. Essa resposta não evita a propagação da infecção e acredita-se que ajude na manutenção do agente infeccioso (Mendoza et al. 1996), já que nessas lesões observa-se grande quantidade de hifas intralesionais. Uma mudança na resposta imunológica é observada em eqüinos tratados com imunoterápicos; nesses casos se observa o desaparecimento da reação eosinofílica e o surgimento de uma resposta mediada por células mononucleares. Através de estudos histopatológicos observouse que $P$. insidiosum foi aparentemente destruído por essas células, indicando que essa mudança na resposta certamente é a responsável pelo sucesso da imunoterapia (Mendoza \& Newton 2005). Nos bovinos deste relato observou-se uma reação inflamatória granulomatosa circundando escassas hifas, o que possivelmente tenha impedido a propagação da infecção, favorecendo à auto-cura. 
Nos relatos em que a cura espontânea não foi observada (Miller et al. 1985, Pérez et al. 2005) os bovinos foram tratados com vários medicamentos, principalmente à base de iodo e antibióticos, não se obtendo sucesso algum (Miller et al. 1985). Em uma revisão sobre imunologia e imunoterapia de infecções causadas por $P$. insidiosum (Mendoza \& Newton 2005), foi mencionada a comunicação pessoal do uso do imunoterápico na espécie bovina, com resultados muito satisfatórios, porém ainda não havia dados publicados disponíveis a esse respeito.

$O$ teste de ELISA mostrou ser um método seguro e eficaz para o diagnóstico de pitiose em eqüinos (Santurio et al. 2006b). Sua utilização no diagnóstico de pitiose bovina foi raramente relatada (Pérez et al. 2005). Apesar do número limitado de amostras positivas testadas neste estudo, dificultando a padronização deste teste para a espécie bovina nas condições laboratoriais utilizadas, os resultados aqui obtidos são importantes devido aos poucos relatos existentes e poderão ser utilizados comparativamente em trabalhos futuros que utilizem essa técnica como método diagnóstico de pitiose bovina.

A técnica de imuno-histoquímica aplicada neste caso foi imprescindível para a confirmação do diagnóstico, já que a cultura do agente não pôde ser realizada. Essa técnica, que utiliza anticorpo policlonal (anti-soro) produzido em coelho, marca especificamente hifas de $P$. insidiosum (Brown et al. 1988) e tem a vantagem de ser aplicada em tecidos fixados em formol (Brown et al. 1988, Chaffin et al. 1995), possibilitando estudos retrospectivos.

A técnica de IHQ, a reação em cadeia de polimerase (PCR) e análises de immunoblot têm sido utilizadas para diferenciar pitiose de outras lesões, como as causadas pelos zigomicetos dos gêneros Conidiobolus e Basidiobolus, que morfologicamente se parecem muito com os casos de pitiose, especialmente na espécie eqüina (Ginn et al. 2007). Outra doença que macroscopicamente se assemelha às lesões nodulares multifocais causadas por $P$. insidiosum em bovinos é a dermatose nodular infecciosa (lumpy skin disease), causada por um poxvírus do gênero Capripoxvirus. Esta doença é exótica no Brasil e caracteriza-se pela formação de lesões cutâneas nodulares, firmes e circunscritas. Entretanto, essas duas enfermidades são totalmente distintas histologicamente e a dermatose nodular infecciosa cursa com linfadenopatia generalizada (Ginn et al. 2007), a qual não é descrita na pitiose bovina.

As informações epidemiológicas e clinico-patológicas descritas neste trabalho fornecem dados importantes so- bre a pitiose cutânea em bovinos. Dois aspectos que chamaram a atenção foram a apresentação em forma de surto afetando 76 bovinos e a cura espontânea de todos os animais afetados. A técnica de IHQ e o teste de ELISA mostraram-se eficientes na confirmação do diagnóstico de pitiose, principalmente devido à impossibilidade de confirmação através da cultura e identificação do agente.

Agradecimentos.- Ao Médico Veterinário H. Pradebon pelas ilustrações das lesões macroscópicas.

\section{REFERÊNCIAS}

Alexopoulos C.J., Mims C.W. \& Blackwell M. 1996. Phylum Oomycota, p.683-737. In: Alexopoulos C.J., Mims C.W. \& Blackwell M. (Ed.), Introductory Mycology. 4th ed. John Wiley and Sons, New York.

Brown C.C., McClure J.J., Triche P. \& Crowder C. 1988. Use of immunohistochemical methods for diagnosis of equine pythiosis. Am. J. Vet. Res. 49(11):1866-1868.

Chaffin M.K., Schumacher J. \& McMullan W.C. 1995. Cutaneous pythiosis in the horse. Vet. Clin. North Am., Equine Pract. 11(1):91103.

Ginn P.E., Mansell J.E.K.L. \& Rakich P.M. 2007. Skin and appendages, p.553-781. In: Maxie M.G. (Ed.), Jubb, Kennedy, and Palmer's Pathology of Domestic Animals. Vol.1. 5th ed. Saunders Elsevier, Philadelphia.

Leal A.B.M., Leal A.T., Santurio J.M., Kommers G.D. \& Catto J.B. 2001. Pitiose eqüina no Pantanal brasileiro: aspectos clínicopatológicos de casos típicos e atípicos. Pesq. Vet. Bras. 21(4):151-156.

Mendoza L., Ajello L. \& McGinnis M.R. 1996. Infections caused by the oomycetous pathogen Pythium insidiosum. J. Med. Mycol. 6:151-164.

Mendoza L. \& Newton J.C. 2005. Immunology and immunotherapy of the infections caused by Pythium insidiosum. Med. Mycol. 43:477486.

Mendoza L., Arias M., Colmenarez V. \& Perazzo Y. 2005. Intestinal canine pythiosis in Venezuela confirmed by serological and sequencing analysis. Mycopathologia 159(2):219-222.

Miller R.I. \& Campbell S.F. 1982. Clinical observations on equine phycomycosis. Aust. Vet. J. 58:221-226.

Miller R.I., Olcott B.M. \& Archer M. 1985. Cutaneous pythiosis in beef calves. J. Am. Vet. Med. Assoc. 186(9):984-986.

Pérez R.C., Luis-León J.J., Vivas J.L. \& Mendoza L. 2005. Epizootic cutaneous pythiosis in beef calves. Vet. Microbiol. 109:121-128.

Santurio J.M., Monteiro A.B., Leal A.T., Kommers G.D., Sousa R.S. \& Catto J.B. 1998. Cutaneous pythiosis insidiosi in calves from the pantanal region of Brazil. Mycopathologia 141:123-125.

Santurio J.M., Alves S.H., Pereira D.B. \& Argenta J.S. 2006a. Pitiose: uma micose emergente. Acta Scientiae Veterinariae 34(1):1-14.

Santurio J.M., Leal A.T., Leal A.B.M., Alves S.H., Lübeck I., Griebeler J. \& Copetti M.V. 2006b. Teste de ELISA indireto para o diagnóstico sorológico de pitiose. Pesq. Vet. Bras. 26(1):47-50. 